\title{
The use of slang amongst undergraduate students of a Malaysian public University
}

\author{
Firooz Namvar \\ University Kebangsaan (National) Malaysia, \\ firooznamvar@gmail.com
}

\begin{abstract}
Slang is the use of highly informal words and expressions that are not considered standard in the speaker's dialect or language. Slang is very often colloquial: the language and dialect tend to be specific to a particular territory. Slang is a central part of young generation's experience, but contrary to many adults perception of slang as more or less uniform "youth language". The social meaning of slang is as variable as the teenagers who use it. In short, slang is an integral part of teenage communication. It gives them an identity of youth style of expression. Though slangs are language and culture specific, but they are often transmitted from one culture and language to another. Recent electronic communications contribute a lot in this process. The aim of this study was to show that if Malaysian youth use English slang in their language. The two major objectives were: 1. to illustrate if Malaysian youth are familiar with slang. 2. To examine what kind of slang they use more in compare with other kinds of slang. A pilot-test consists of 20 slang items was administered to 60 students. The respondents were in final semester of bachelor of English language at UPM. The data obtained from the study was coded and analyzed using the statistical package for social sciences (spss). The analyzing of data showed that the internet slang, abbreviations slang, and movie slang are used frequently by youth generation. It seems that they are familiar with these sorts of slang. The reasons can be because of using internet a lot nowadays, another reason can be media, which has the most important role in this case.
\end{abstract}

\section{Indexing terms/Keywords}

Slang; second language acquisition; youth language; colloquial.

\section{Council for Innovative Research}

\author{
Peer Review Research Publishing System
}

Journal: Journal of Advances in Linguistics

\author{
Vol 3, No. 1 \\ editor@cirworld.com \\ www.cirworld.com, member.cirworld.com
}




\section{INTRODUCTION}

This study will show the amount of familiarity of slang, particularly American slangs, amongst Malaysian undergraduate students of a public university. English language is constantly changing and slang is increasingly becoming a greater part of our shifting linguistic terrain. Most new words, in fact, come from slang. In the recently released 2000 edition of The Random House Webster's Collegiate Dictionary, there are 303 new words among the 200,000-plus definitions. Most come from slang, often seen as the language of youth. Slang an ever-changing set of Colloquial words and phrases generally considered distinct from and socially lower than the standard language. Slang is used to establish or reinforce social identity and cohesiveness, especially within a group or with a trend or fashion in society at large. It occurs in all languages, and the existence of a short-lived vocabulary of this sort within a language is probably as old as language itself. In 1938 slang was defined as coming from 'money, sex and intoxicating liquor'. Add in drugs and very little has changed. Nor is it likely to. Standard English has most of the words it needs; slang continues to expand. The patterns will remain, the need for slang to retain even a short-term secrecy means that the lists of synonyms will keep expanding.

\section{LITERATURE REVIEW}

Slang refers to speech expressions used by a speech community (e.g. teenagers, criminals, etc.) that wishes to show its attachment to a favorable social identity; a usage which is not often approved of by other social groups (Hashemi, 2011). It is a style of usage that is not acceptable in situations outside the group and is unfavorable to the general population. Hudson (2000) believes that slang starts out as clever alternative ways of saying things which could otherwise be expressed in polite ways. On the other hand, Allan and Burridge (2009) argue that the politeness of this category of language is wedded to context, time and place. Eble argues that; slang is an ever changing set of colloquial words and phrases that speakers use to establish or reinforce social identity or cohesiveness within a group or with a trend or fashion in society at large. The existence of vocabulary of this sort within a language is possibly as old as language itself, for slang seems to be part of any language used in ordinary interaction by a community large enough and diverse enough to have identifiable subgroup (1996:11).

Some sociolinguistic and lexicographic research on teenage and young adult slang (e.g., Eble 1996; Charkova 2007; Munro 1989; Sutton 1995) has documented the wealth of lexical resources available to speakers in the creation and display of youth identity. Yet these studies, which rely on written self-reports of usage, do not always make clear to what degree their data derive from language ideologies and to what degree they represent actual patterns of slang use; respondents' stereotypes, attitudes, and ideologies of how slang is used are often presented unproblematically as reflective of linguistic practice. It is therefore advisable to read these research reports not as straightforward documentations of slang use but mainly for the valuable information they yield about language ideology.

Such studies, given their methods and goals, also offer up ideologies of their own. Primary among these is the representation of slang as a unifying practice that consolidates youth identity in opposition to adults. Like most ideologies, this one has a factual basis: it has been widely observed that slang, at least beginning in the latter half of the twentieth century, has served as one strategy among others for establishing and maintaining a teenage cohort separate from adults on the one hand and children on the other. From this perspective, slang is a kind of "anti-language," to use Halliday's (1976) term, or, in Morgan's (1993) revision of Halliday, a "counterlanguage," through which a shared youth identity is reproduced against a dominant norm. But in highlighting this function of slang, sociolinguists have downplayed the ways in which it divides as well as unifies its users.

Evelyn (2006) in India has done a research on Indian students' use of slang. She investigated the influences of slang on society also. She has used the descriptive method and used interviews and questionnaires to collect the data, without considering the secondary sources such as books, articles, and most important thing, Internet. Actually, she investigated the specific slang expressions used by Indians students on a University campus. All the slang is in the Indian language and she gives the definitions in English. Also she doesn't consider different kinds of slang such as Internet slang, movies slang, street slang, etc. She focused on campus slang at a University in India only.

In Malaysian universities most of undergraduate students speak English. Thus, as English is the language of the computer and the internet and as well the language of Hollywood movies, it is important for students to be familiar with contemporary English and slang will be a significant part of this. Research conducted on slang amongst undergraduate students seems very limited. The majority of materials available in this area are dictionaries or thesauruses that list slang examples in a given language but often do not define the specific terms of colloquial speech and slang. Thus this study was conducted to begin an investigation into whether Malaysian students are familiar with slang.

\section{METHODOLOGY}

In this study a pilot-test was used to establish the validity and reliability of the instrument. While validity refers to whether or not an instrument measures what it is supposed to measure, reliability refers to how consistently the instrument yields the same results over repeated trials. The pilot- testing helped to determine if the tests are straight forward and easily understood by the respondents. In this test both correct and incorrect answers were important to researcher. Because the correct answers tell the researcher that students are familiar with slang and incorrect answers mention that, students are not familiar with this slang. The test for this study consisted of 20 items. slang items for this study were collected from www.intranet.csupomona.edu/ jasanders/slang/index.html where top 20 slang of each year are mentioned. Then the selected items were checked with the third edition of Dictionary of American slang and colloquial Expressions to be sure about the accuracy of meaning of slangs. 
According to Tuckman (1978), the item in a pilot-test, would be re-tested to find out its clarity and distribution. First the pilot-test was administrated to 10 students, 4 Iranians, 2 Jordanians, 1 Bangladeshi, and 3 Malaysians. All of them were students at UPM. The age of respondents ranged from 20 to 30 and the average is 25.8. In the pilot-test there are 20 items. Each item has four possible responses. After analyzing the first data, the results showed that students are familiar with slang and the test can be administered to the participants.

Respondents' frequencies of use of slangs in English were obtained through a pilot-test. The instrument consisted of 20 items on slangs in the form of multiple choices. Respondents were requested to report their frequency of use of these items to know whether they were familiar with these slangs and if they use these slangs in their use of English. The responses of the respondents were computed through SPSS.

\section{The Participants}

The respondents for the study were 60 final semester Bachelor of English Language at UPM. The 60 respondents comprised both male and female students. Respondents of this study were from both male and female groups. The percentage of male respondents was 15 whereas the percentage of female was 85 . Since this study did not aim to explore influence of gender on the use of slang, variation of respondents on gender was not considered important. They were not given a specified time to respond to the test. This was to enable the respondents to respond to the test in a very comfortable and convenient manner.

\section{Data Analysis}

All the data obtained from the study was coded and analyzed using the statistical package for social sciences (SPSS). All the items were divided into variables for data processing and analyzing using the computer. Data was analyzed according to gender, age, nationality. The data was analyzed through a linguistic point of view.

\section{RESULTS AND DISCUSSION}

The following sections discuss the frequencies of use of these slangs by the respondents.

Slang No. 1. Yep (yup): you, yes, strong, below

The meaning of this slang is yes, a positive answer, originality in 1960 s entered to language. It is very common in everyday language as majority of people use this slang in their conversations. Respondents' frequency of use of the slang 'Yep' is presented in table 1 Of the total respondents, $98.3 \%$ reported correct answer and $1.7 \%$ reported incorrect answer to mark their familiarity with this slang. Since, majority of the respondents (98.3\%) chose the correct answer, it seems that they are familiar with this slang and they might use this slang in their use of English. Respondents irrespective of gender and nationality reported to be familiar with this slang which indicates that this particular slang is used across the gender, nationality, and culture.

Slang No. 2. Baby: child, infant, young child, somebody you love (your love)

Baby in slang means sweetheart, somebody you love. Its origin is belongs to 1940s. Respondents' frequency of use of the slang 'Baby' is presented in table 1 Of the total respondents, 35\% reported correct answer and 65\% reported incorrect answer to mark their familiarity with this slang. Since, majority of the respondents $(65 \%)$ chose the incorrect answer, it seems that they are not familiar with this slang and they might not use this slang frequently in their use of English. There should be some reasons that respondents were not familiar with this slang. One of them may be related to their culture. Most of the respondents are Malaysian and as the results tell the researcher this slang is not a common slang in society of Malaysia and among the students. The other reason can be because of not being so intimate to each other to call each other like that, then normally they were not familiar with this slang.

Slang No. 3 Chicken: coward, white meat, ugly, bad

This slang refers to a person who is coward. This slang also entered the language in 1940s. Since that year it could stay as a common slang so far. Respondents' frequency of use of the slang 'Chicken' is presented in table 1 Of the total respondents, $23.3 \%$ reported correct answer and $76.7 \%$ reported incorrect answer to mark their familiarity with this slang. Since, majority of the respondents (76.7\%) chose the incorrect answer, it seems that they are not familiar with this slang and they might not use this slang frequently in their use of English.

Slang No.4 Big Mouth: important, young man, silent, talks too much

Big mouth means a talkative person and it refers to 1980s. Respondents' frequency of use of the slang 'Big mouth' is presented in table 1 Of the total respondents, $71.7 \%$ reported correct answer and $28.3 \%$ reported incorrect answer to mark their familiarity with this slang. Since, majority of the respondents $(71.7 \%)$ chose the correct answer, it seems that they are familiar with this slang and they might use this slang in their use of English.

\section{Slang No.5 Cool: Coldness, Great, Crazy, lazy}

Cool in slang means excellent or great. It refers to 1950s. Respondents' frequency of use of the slang 'Cool' is presented in table 4.3. Of the total respondents, $88.3 \%$ reported correct answer and $11.7 \%$ reported incorrect answer to mark their familiarity with this slang. Since, majority of the respondents (88.3\%) chose the correct answer, it seems that they are 
familiar with this slang and they might use this slang in their use of English. It's accepted by young culture to use it. The main reason for being so popular can be media.

Table 1: Respondents' frequencies of use of slang no. 1 to 5

\begin{tabular}{|l|c|c|c|c|}
\hline & Total valid & \% of valid & Total invalid & \% of invalid \\
\hline Slang No. 1 & 59 & 98.3 & 1 & 1.7 \\
\hline Slang No. 2 & 21 & 35 & 39 & 76.7 \\
\hline Slang No. 3 & 14 & 23.3 & 46 & 28.3 \\
\hline Slang No. 4 & 43 & 71.7 & 7 & 11.7 \\
\hline Slang No. 5 & 53 & 88.3 & 77 & 76.7 \\
\hline
\end{tabular}

\section{Slang No. 6 Gonna: well, going to, displace, want}

The original form of gonna is going to, normally it accepted by people to use it in slang are and according to our result the answer of being with this slang is positive. Normally young people use this form of slang in the internet and writing sms. Respondents' frequency of use of the slang 'Gonna' is presented in table 2 Of the total respondents, $88.3 \%$ reported correct answer and $11.7 \%$ reported incorrect answer to mark their familiarity with this slang.

\section{Slang No.7 Gotta: Got to, Forgotten, Unable to do, Shortage}

The same as the previous slang this one is a reduction. The meaning of this word is got to, must, and need to but in the area of slang people use it as goota. Respondents' frequency of use of the slang 'Gotta' is presented in table 2 Of the total respondents, 95\% reported correct answer and 5\% reported incorrect answer to mark their familiarity with this slang. Since, majority of the respondents (95\%) chose the correct answer, it seems that they are familiar with this slang and they might use this slang in their use of English.

Slang No.8 Wanna: Request, Want to, Lust, Dream

Want to is the complete form of wanna as a slang. This slang is very common as accepted by youth culture and they use it frequently in their conversations. Respondents' frequency of use of the slang 'Wanna' is presented in table 2 Of the total respondents, 95\% reported correct answer and 5\% reported incorrect answer to mark their familiarity with this slang.

Table 2: Respondents' frequencies of use of slang No. 6 to 8

\begin{tabular}{|l|c|c|c|c|}
\hline & Total valid & \% of valid & Total invalid & \% of invalid \\
\hline Slang No. 6 & 53 & 88.3 & 7 & 11.7 \\
\hline Slang No. 7 & 57 & 95 & 3 & 5 \\
\hline Slang No. 8 & 57 & 95 & 3 & 5 \\
\hline
\end{tabular}

Slang No. 9 LOL (short form, Internet abbreviation): laughing in a loud voice (many laughs), long life, happy, lonely

LOL (also written lol) is an abbreviation for "laugh out loud", "laughing out loud "lots of laughter", "lots of laughs". LOL is a common element of Internet slang used, historically, on Usenet. It is similar to the acronyms, which are used to communicate a higher degree of amusement. Evidence of this phrase has been located as far back as a Usenet posting on January 17, 1990. Respondents' frequency of use of the slang 'LOL' is presented in table 3. Of the total respondents, $76.7 \%$ reported correct answer and $23.3 \%$ reported incorrect answer to mark their familiarity with this slang. Since, majority of the respondents (76.7 \%) chose the correct answer.

Slang No.10 ASAP: As soon as possible, See you later, As a problem, Possibility

ASAP is an abbreviation, which means as soon as possible. This is internet slang as well. It's very common nowadays in the net and the high percent of correct answers confirms the claim. Most of young people, especially students use this slang in their email and in the chatting as well in their sms. Respondents' frequency of use of the slang 'ASAP' is presented in table 3 . All the respondents, $100 \%$ reported correct answer to mark their familiarity with this slang. Since, all the respondents (100\%) chose the correct answer.

Slang No.11 Brb (Internet slang): be right back, I'm very busy, Be great, Be good

BRB is an abbreviation for 'be right back'. It's very popular slang among students. Normally they use it in the chartroom and email and on the hand phone for writing an SMS.

Slang No. 12 B4N: (internet slang) before, bye, Bye for now, Be right back 
B4N is another abbreviation in the area of slang. Again the area of use of this slang is on the net specially chatting and email. It's a very popular slang among the students nowadays which started in 1990s. Respondents' frequency of use of the slang 'B4N' is presented in table 3.

Table 3: Respondents' frequencies of use of slang no. 9 to 12

\begin{tabular}{|l|c|c|c|c|}
\hline & Total valid & \% of valid & Total invalid & \% of invalid \\
\hline Slang No. 9 & 46 & 76.7 & 14 & 23.3 \\
\hline Slang No. 10 & 60 & 100 & 00 & 00 \\
\hline Slang No. 11 & 60 & 100 & 00 & 00 \\
\hline Slang No. 12 & 53 & 88.3 & 7 & 11.7 \\
\hline
\end{tabular}

Slang No.13 What's up? What's that?, What a pity?, What's the problem?, What's going on? (How are you?)

This slang means, what's going on? What's new? How do you feel?

In everyday conversation we use this slang. Intentionally or not we are using slang anyway. This slang refers to 1940 s. Respondents' frequency of use of the slang 'What's up' is presented in table 4.

Slang No.14 My Bad: goodness, My mistake, Silly, My favorite

My bad as a slang means: my mistake. It refers to 1970s and so far could stay as a common slang among the people especially young people. Respondents' frequency of use of the slang 'My bad' is presented in table 4. Of the total respondents, $51.7 \%$ reported correct answer and $50.3 \%$ reported incorrect answer to mark their familiarity with this slang. Since, about half of the respondents chose the correct answer and half of them chose incorrect, it seems that respondents are partially familiar with this slang and they might use this slang partially in their use of English.

Slang No.15 Pic: computer, picture, show, icon

Another abbreviation in the slang area is pic, which normally is used as a picture. This slang is very popular internet slang. Young people use it mostly in their email and chat. Respondents' frequency of use of the slang 'Pic' is presented in table 4

Slang No. 16 Dude: good, cool guy, adult male, ugly

Dude is an American slang, which means a cool guy. It refers to 1950s and still young people use it often. As this slang is an American and normally used in that society we can see that it's not so popular here among the students. Respondents' frequency of use of the slang 'Dude' is presented in table 4.

Table 4: Respondents' frequencies of use of slang no. 13 to 16

\begin{tabular}{|l|c|c|c|c|}
\hline & Total valid & \% of valid & Total invalid & \% of invalid \\
\hline Slang No. 13 & 50 & 83.3 & 10 & 16.7 \\
\hline Slang No. 14 & 31 & 51.7 & 29 & 50.3 \\
\hline Slang No. 15 & 60 & 100 & 00 & 00 \\
\hline Slang No. 16 & 32 & 53.3 & 28 & 46.7 \\
\hline
\end{tabular}

Slang No.17 Oh Jesus Christ! Jesus, message, Expression of surprise, good

Oh Jesus Christ shows the surprise. It can be as movie slang as mostly can be heard in the movies. And can be mention as media slang. Because of western movie and Hollywood movies this slang is popular now, but if we consider as a cultural or if we relate it to religion it cannot be a popular slang here in Malaysia.

Slang No.18 Oh Shit! Meaningless, oh no, damn, deceive, kind

It is a Slang in the area of media, which means, 'oh no or damn'. It's popular because of the media and TV channels. As the percentage of correct answer says it is accepted by youth culture and counts as a popular slang among students and people. Respondents' frequency of use of the slang 'Oh Shit' is presented in table 5.

Slang No. 19 Homey: a friend or buddy, difficult, cruel, like a home

Homey means a friend or a buddy. It refers to 1980s. It's not a very common slang among the students as the results tell us. Respondents' frequency of use of the slang 'Homey' is presented in table 5. Of the total respondents, 25\% reported correct answer and $75 \%$ reported incorrect answer to mark their familiarity with this slang. Since, majority of the 
respondents $(75 \%)$ chose the incorrect answer, it seems that they are not familiar with this slang and they might not use this slang frequently in their use of English.

\section{Slang No.20 Oh my goodness! Expression of surprise or shock, Very bad, Good, Kindness}

'Oh my Goodness' shows the surprise or shock. According to amount of correct answer can be mention as a popular slang among students. The affect of popularity can be the media, especially western media. Respondents' frequency of use of the slang 'Oh my goodness' is presented in table 5.

Table 5: Respondents' frequencies of use of slang no. 17 to 20

\begin{tabular}{|l|c|c|c|c|}
\hline & Total valid & \% of valid & Total invalid & \% of invalid \\
\hline Slang No. 17 & 57 & 95 & 3 & 5 \\
\hline Slang No. 18 & 60 & 100 & 00 & 00 \\
\hline Slang No. 19 & 15 & 25 & 45 & 11.7 \\
\hline Slang No. 20 & 53 & 88.3 & 7 & 75 \\
\hline
\end{tabular}

It can be seen in Tables 1, 2, 3, 4, and 5 that majority of the respondents were familiar with most of these slangs. Only in three slangs, slangs No. 2, 3, and 19 respondents were not found acceptably familiar.

\section{CONCLUSION}

Slang as defined, is a set of colloquial words or phrases in a language. By nature it is ever changing resulting from different factors such as socio-cultural changes and advancement, technological development and mass media, the process of acculturation and globalization, evolution and natural development of language. Language by nature is dynamic. Every language is changing, modifying and developing with the change of social structured, cultural values and norms, communicative needs, behavior and strategies, mode of communication, etc. in the passage of time. As language evolution is a continuous process, words modifying in this structure and function, some of them are dying out because of no or less currency in their use among the members of the speech community, and at the same time, many new words are coming into scene and enriching the word-stock of languages. The new words and phrases are adding to the list of words through different word formation processes. Slang, a type of word is also made through different process of word formation. Some of them have a very short span of existence whereas some are as old as the language itself.

Slang is generally perceived as the language of the youth. It seems as a part of youth culture and styles. People of young generation use slang for multidimensional purposes. Sometimes slangs are used as secret code among the youth. When they want their speech should not be understood by the people of other generations. Sometimes slangs are used to make fun and enlightenment in the friendly discussion and gossip among the youth. The most important function of slang is identity marker. It identifies the youth from the other generations.

By nature, slang seems to be language and cultural specific. But with the advancement of electronic communication, internet and cell phone in particular, slang of our language and culture passes to another language and culture. In the multicultural and multilingual settings, the frequency of mixing up of slang into language is high.

Slang of our language and culture may influence the other language and culture. This study examined whether the Malaysian undergraduates use slang. If they use, to what extent they are familiar with slang. This study also explored the sources of slag as internet, books, and papers, and media.

The analysis of data shows that internet slang and abbreviations such as gonna, gotta, pic, B4N, BRB, LOL, ASAP, and wanna are used frequently by youth generation. It seems that they are familiar with this sort of slang. On the other hand some slangs such as baby, chicken, my bad and dude couldn't attract the respondents' attention, which means they are not familiar with this kind of slang in compare with internet slang. As the study says they are also familiar with slangs like Oh shit! Oh my goodness! and Oh Jesus Christ!. We can hear this kind of slang normally in the movies. It can be a reason why they are familiar with this kind of slang. It shows the influence of media on youth generation language. As most of TV channels in Malaysia are American channels, it is predictable that youth generation be familiar with media slang or movie slang, which shows most of slang they use are American slang.

In short, slang is an integral part of teenage communication. It gives them an identity of youth style of expression. Though slangs are language and culture specific, but they are often transmitted from one culture and language to another. Recent electronic communications contribute a lot in this process.

\section{REFERENCES}

[1] Allan, K. \& Burridge, K. 2009. Forbidden words: Taboo and censoring of language. Cambridge: Cambridge University press.

[2] Charkova, K. 2007. A language without borders: English slang and Bulgarian learners of English. Language Learning. 57(3), 369-416. 
[3] Eble, Connie, 1996. Slang and Sociability: in-group language amongst college students.Chapel Hill: University of North Carolina Press.

[4] Evelyn, R. 2006. Student Slang at IIT Madras. Delhi, India.

[5] Halliday, M. A. K. 1976. Anti-languages. American Anthropologist. 78, 570-84.

[6] Hashemi, S. 2011. Analyzing Slang Usage among Iranian Male and Female Teenagers. English language teaching, 4 (2), 198-205.

[7] Hudson, G. 2000. Essential Introductory Linguistics. Oxford: Blackwell.

[8] Morgan, M. 1993. The Africanness of counterlanguage among Afro-Americans. In Salikoko S. Mufwene, ed., Africanisms in Afro-American language varieties. Athens: University of Georgia Press. 423-435.

[9] Munro, P. 1989. Slang U: The official dictionary of college slang. New York: Harmony Books.

[10] Sutton, L. A. 1995. Bitches and skankly hobags: The place of women in contemporary slang. In Kira Hall \& Mary Bucholtz, eds., Gender articulated: Language and the socially constructed self. New York: Routledge. 279-296.

[11] Tuckman, B., 1978. Conducting Educational Research. Harcourt Brace Jovanovitch: San Diego.

\section{APPENDIX}

The test which was used for this study consisted of 20 items. The selected items were checked with third edition of Dictionary of American slang and colloquial Expressions to be sure about the accuracy of meaning of slangs.

Slang test

Gender: $\quad$ Dge:
The answers are marked by $\left(^{*}\right)$
1. Yep(yup):
a. you
b. yes ${ }^{*}$
c. strong
d. blow
2. baby:
a. child
b. infant
c. young child
d. somebody you love (your love) ${ }^{*}$
Chicken:
a. Coward ${ }^{*}$
b. white meat
c. ugly
d. bad

4. big mouth:
a. important
b. young man
c. silent
d. talk too much*

5. Cool:
a. Coldness
b. Great, excellent ${ }^{\star}$
c. Crazy
d. Lazy 
6. gonna:
a. well
b. going to*
c. displace
d. want

7. Gotta:
a. Got to*
b. Forgotten
c. Unable to do
d. Shortage

8. Wanna:
a. Request
b. Want to*
c. Lust
d. Dream

9. LOL (short form, Internet abbreviation):
a. laughing in a loud voice (many laughs)*
b. long life
c. happy
d. Ionely

10. ASAP:
a. As soon as possible*
b. See you later
c. As a problem
d. Possibility

11. Brb (Internet slang):
a. be right back*
b. I'm very busy
c. Be great
d. Be good

12. B4N: (internet slang)
a. before
b. bye
c. Bye for now ${ }^{\star}$
d. Be right back

13. What's up?
a. What's that?
b. What a pity?
c. What's the problem?
d. What's going on? (How are you?)

14. My bad: 

a. goodness
b. My mistake*
c. Silly
d. My favorite

15. pic:
a. computer
b. picture $^{*}$
c. show
d. icon

16. Dude:
a. good
b. cool guy *
c. adult male
d. ugly

17. Oh Jesus Christ!
a. Jesus
b. message
c. Expression of surprise*
d. good

18. Oh Shit!
a. meaningless
b. oh no, damn*
c. deceive
d. kind

19. Homey:
a. a friend or buddy
b. difficult
c. cruel
d. like a home

20. Oh my goodness!
a. Expression of surprise or shock*
b. Very bad
c. Good
d. Kindness 